\title{
Hybrid improvement and reconstruction based on prognostic breeding selection criteria
}

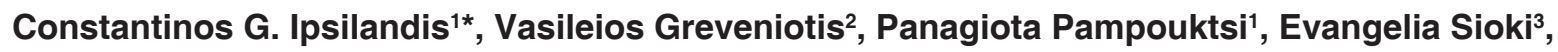 \\ Fanis A. Tsapikounis ${ }^{4}$ \\ ${ }^{1}$ Regional Administration of Central Macedonia, Department of Agriculture, Thessaloniki 54622, Greece, ${ }^{2}$ Department of Agricultural \\ Technology, Technological Educational Institute of Thessaly, Larissa 41110, Greece, ${ }^{3}$ Department of Agricultural Economics, Aristotle \\ University of Thessaloniki, Thessaloniki 54124, Greece, ${ }^{4}$ FytoDiagnosi, Plant Clinic, 36 Deligianni Str, Pirgos 27100, Greece
}

\section{A B S T R A C T}

In order to faster and more efficiently select maize inbred lines as parents for maize hybrids, a multi-year evaluation was conducted under both honeycomb methodology schemes and classic randomized complete block designs. Combined yield and stability calculations were used. The initial genetic material was developed from F2 of a commercial F1 maize hybrid.1200 F2 plants were used at an intrarow distance of $1.25 \mathrm{~m}$ and the inter-row distance was $1.08 \mathrm{~m}$ in a NR-0 honeycomb design. Combined Half-sib and S1 evaluation was performed for oriented crosses. After successive selfing generations S1 to S7 progenies were developed. Three types of crosses were performed a) Formation of HS families, b) Diallel crosses between S4 and also S5 recombinant lines, and c) Crosses of these lines to the freely available inbred line B73. Crosses between high yielding S-lines to common foreign parent led to limited heterotic phenomena and relative low yielding performance. Heterobeltiosis was found near zero or negative, proving that such kind of parents cannot contribute in high yielding crosses because of the accumulation of useful additive alleles in the improved parent, and additive alleles are not favoured in heterozygote condition. Crosses between improved lines were generally high, but they based their productivity mainly on additive gene action. Prognostic breeding is more accurate when selection is applied for exploitation of additive gene action. CV was a good stability criterion, but CC proved confusing for selecting crosses. Productivity index $P$ exhibited the superiority of the best lines that showed high and stable performance across years. The procedure resulted in high yielding inbred lines bypassing population improvement and thus shortened the whole evaluation process.

Keywords: Additive genes; Crosses; Productivity index P; Second-cycle

\section{INTRODUCTION}

Modern maize (Zea mays L.) breeders prefer genetically narrow-based populations (Hallauer, 1979) including eliteline synthetics of narrow genetic base, F2 populations of single crosses and backcross populations. Thus, inbred development includes primarily elite inbred crosses, backcross and synthetic populations (Bauman, 1981). For successful genetic recycling, the choice of elite germplasm is very important (Fasoulas, 1988; Duvick, 1996). Developing new hybrids depends not only on the germplasm but also on the selection procedure for developing inbred lines to serve as hybrid parents, which is the final target considering maize. Hybrid yield is depended mainly on heterosis which improves total field performance of maize plants and is attributed mainly on dominant allele effects (Smith,
1984; Falconer, 1989; Kearsey and Pooni, 1992). Fasoulas $(1988,1993)$ considered that heterosis, although a positive phenomenon (Fehr, 1987), has a "dark side" by encrypting deleterious recessive alleles in heterozygote loci found in repulsing phase linkage. Thus, "pseudo-overdominant" effects may occur in such cases and the positive dominant allele plays a double role: a positive addition on yield and deleterious recessive repression.

The yielding distance between $\mathrm{F}_{1}$ maize hybrids and inbred lines or $\mathrm{F}_{2}$ generations was found significant (Vafias and Ipsilandis, 2005) as a result of exploitation of heterosis (Tollenaar et al., 2004). Ipsilandis et al. (2006) reported that hybrid reconstruction by recycling may lead to the exploitation of positive additive gene action. This is a result of per se improvement of inbred lines based on

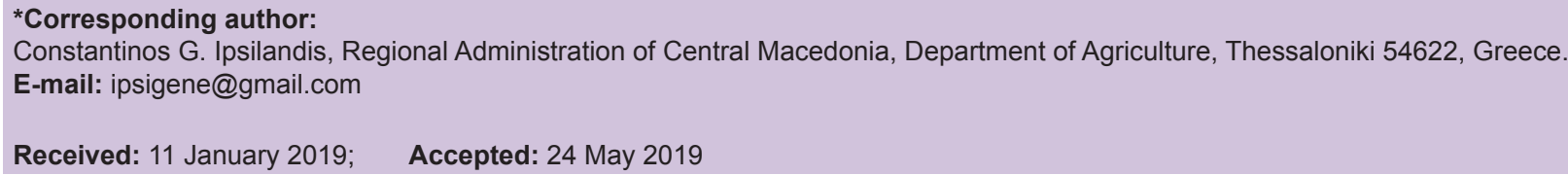


additive genes that increase yielding performance. This procedure may avoid population improvement since productivity is based on already improved lines (Ipsilandis \& Koutsika-Sotiriou, 2000). As far as parental inbred lines yield improves, the less $\mathrm{F} 1$ cross yielding performance depends on heterosis and heterozygosity (Ipsilandis et al., 2005). Thus, it is important to have elite inbred lines with high productivity in order to partly support yield of modern maize hybrids and also to ensure sufficient (and cheap) seed production (Duvick, 1999, 2001; Ipsilandis \& Koutsika-Sotiriou, 2000). Additionally, Crow (2000) also reported that additive genetic action (with partial to complete dominance) is the dominant kind of gene action in the expression of yield in maize. Nevertheless, Midparent heterosis (Fehr, 1987) expressed as yield superiority of the hybrid in comparison to its parents is still the final product of a breeding program, resulting in high yielding and stable genetic materials.

Prognostic breeding is a new approach to accelerate the progress of genetic improvement through selection by evaluating two main components: plant yield potential and stability of performance (Greveniotis and Fasoula, 2016). Plant yield and stability are calculated using plant prognostic equations. They reported that prognostic breeding led to the isolation of superior maize lines whose productivity was comparable to F1 commercial single-cross hybrid Costanza (around $90 \%$ of yielding performance). Across all cycles, the average annual genetic gain ranged from $23 \%$ to $36 \%$ by applying honeycomb methodology selection schemes. The novelty in prognostic honeycomb methodology is that evaluation for yield and stability genes is accomplished in the same generation by evaluating the crop yield potential of each individual plant. Many formulas were proposed previously to accelerate the breeding procedure under honeycomb methodology schemes. In historic basis, Fasoulas (1981) and KoutsikaSotiriou (1985), proposed combination of mean yield and Coefficient of Variation $(\mathrm{CV} \%)$ for estimating productivity and stability together with productivity index $P$, a statistical parameter (\%) measuring statistically differences (estimated distances) between the mean values of genetic materials and thus showing how many progeny families of a genetic material are statistically superior. This was the first attempt to improve and shorten the whole evaluation procedure.

Then, the combined criterion CC was initiated for selecting superior genotypes (Fasoula-Ioannides, 1992): $\mathrm{CC}=\bar{x}^{2}(\bar{x}-\mathrm{s}) / \mathrm{s}$ where $\bar{x}$ and $\mathrm{s}$ are the progeny line mean and standard deviation. Koutsika-Sotiriou and Bos (1996) proposed another criterion for evaluating maize inbred lines to be used as hybrid parents: Heterobeltiosis (\%) as computed by the formula: $\mathrm{HB}=(\mathrm{F} 1-\mathrm{P}) / \mathrm{P} \times 100$, where
$\mathrm{F} 1=$ the hybrid yield and $\mathrm{P}=$ the best parent yield or the second parent yield.

Later the A and B prediction and selection formulas were proposed (Fasoula, 2008):

$A=\left(x / \bar{x}_{r}\right)^{2} \cdot(\bar{x} / s)^{2}$ and $B=\left(\bar{x} / \bar{x}_{t}\right)^{2} \cdot(\bar{x} / s)^{2}$ where $x$ is the single-plant yield, $\bar{x}_{r}$ is the average yield of the surrounding plants within a moving ring of a chosen size, $\bar{x}_{t}$ is the overall experimental mean and $\bar{x}$ and $\mathrm{s}$ are the progeny line mean and standard deviation. Now the new formula pPE is used (Greveniotis and Fasoula, 2016): $\mathrm{pPE}=\left(x / \bar{x}_{r}\right)^{2} \cdot\left(\bar{x}_{g} / s\right)^{2}$ where $x$ is the single-plant yield, $\bar{x}_{r}$ is the average yield of the surrounding plants within a moving ring of a chosen size, $\bar{x}_{g}$ is the mean plant yield of each moving grid and s is the standard deviation.

In order to faster and more efficiently select maize inbred lines as parents for maize hybrids, a multi-year, multicriteria evaluation was conducted under both honeycomb methodology and classic randomized complete block schemes. Combined plant yield and stability estimations were used and the progress of inbred lines per se and their crosses were recorded across generations. The procedure also estimated the efficiency of the criteria used during genotype evaluation.

\section{MATERIALS AND METHODS}

The initial genetic material was developed from F2 generation of a commercial F1 single-cross maize hybrid (Lorena, PR3183), one of the most adapted commercial hybrids in Greece. All field experiment was established at the University Farm of Thessaloniki in northern Greece $\left(22^{\circ} 59^{`} \mathrm{E}, 40^{\circ} 32^{`} \mathrm{~N}\right)$. Local conditions are recorded for a 10-year period (1988-1997) in the archives of the National Meteorogical Society (Greece).

1200 F2 plants were used at an intra-row distance of $1.25 \mathrm{~m}$ and the inter-row distance was $1.08 \mathrm{~m}$ in a NR-0 honeycomb design (Fasoulas, 1981). Each hill was initially planted with a number of seeds and later it was thinned to one seedling to form an ultra-low density of 0.8 plants $\mathrm{m}^{-2}$. A total of 512 S0 plants from the F2 population were chosen by eye-selection on the basis of their vigour and prolificacy. The upper ear of each plant was selfed to produce S1 families and the lower ear was open-pollinated to produce the Half-sib (HS) families.

Next year (first year of evaluation), the S1 lines from the selfed ear and the half-sib (HS) families from the openpollinated ear of each of $512 \mathrm{~F} 2$ plants, were evaluated in comparison to the original single-cross hybrid PR3183. The 
evaluation was made in single progeny line under a moving block design (Fasoulas, 1985; Ipsilandis, 1996). The entries in the field were located in such a way that every S1 row was adjacent to the corresponding HS family (512 pairs S1-HS). Hybrid PR 3183 was the control and sown in 64 rows. The intra-row distance was $40 \mathrm{~cm}$ and the inter-row distance $1 \mathrm{~m}$. The density was 2.75 plants $\mathrm{m}^{-2}$. The plots consisted of $4 \mathrm{~m}$ long single rows of eleven plants. From each S1 line, a single plant was randomly selected and selfed. Fifty S1 lines (about 10\%) were selected to form S2 seed, according to the relative difference in yield with regard to the corresponding HS-family. The HS families were used as initial testers for combining ability in early generations. After successive selfing generations S4, S5, S6 and S7 progenies were developed. Coding of lines was based on line classification according to their S1/HS performance.

Across years, three types of crosses were performed: a) Formation of HS families, b) Diallel crosses between S4 and also S5 recombinant lines, and c) Crosses of the most promising of these lines to freely available inbred line B73 as common parent (Ipsilandis, 1996). Crosses were categorized and programmed after grouping parental inbred lines in yield categories according to their S1 per se yield and HS yield (Goulas \& Lonnquist, 1976; Coors, 1988; Ipsilandis, 1996). Line classification and S1/ HS yield level are presented in Table 1 (two groups 1 and 4 were split in two subgroups). These crosses across years and generations were evaluated in Randomized Complete Block (RCB) designs with 4 replications for all field trials. In all yield tests the experimental plot consisted of two $5 \mathrm{~m}$ long rows, spaced $80 \mathrm{~cm}$ apart. All plots consisted of 50 plants, i.e. 25 plants per row giving a population density of 6.25 plants $\mathrm{m}^{-2}$. The initial F1 single-cross hybrid was included as the main control (PR3165 was also included). The S5, S6 and S7 inbred progenies were evaluated in a separate experiment. Additionally, honeycomb evaluation was used for $\mathrm{S} 3$ progenies and their $\mathrm{S} 2$ crosses in replicated honeycomb designs (R-133) at the ultra-low density of 0.8 plants $\mathrm{m}^{-2}$ (Fasoulas, 1988; Ipsilandis, 1996; Ipsilandis et al., 2006; Greveniotis \& Fasoula, 2016). All plants were grown using conventional fertilizer applications and weed/ pest control in order to promote high productivity. Grain yields were adjusted to $15.5 \%$ grain moisture. The RCB analysis was based on the null hypothesis by means of an analysis of variance at the 0.05 probability level (Gomez $\&$ Gomez, 1984). Proper data handling and moisture adjustment were performed and statistical analysis was made by MSTAT-C academic statistical package. Combined criterion was applied according to Fasoula-Ioannides (1992). Productivity ratio $P$, was calculated according to Koutsika-Sotiriou (1985). Equation B for honeycomb family selection was applied properly according to Fasoula (2008). Coefficient of variation (CV) and data rendering were processed according to Ipsilandis (1996) and, Ipsilandis \& Koutsika-Sotiriou (2000), and CV values were used in the sense of stability estimation as described by Greveniotis et al. (2018, 2019).

\section{RESULTS}

Table 1 presents the s-line classes and their S1/HS productivity (in $\mathrm{g} /$ plant) and stability according to $\mathrm{CV}$ values. Great differences in means were found between classes including, combinations of high yielding S1 or HS progenies and their middle to low-yielding HS or S1 respective progenies. In some cases, $\mathrm{S} 1$ and $\mathrm{HS}$ progenies exhibited high productivity simultaneously. S2XS2 crosses productivity was evaluated in honeycomb design and great differences were revealed (Table 2). Some crosses like A-27XD-17 showed high productivity and the F1

\begin{tabular}{|c|c|c|c|c|c|c|}
\hline No & Class & Progeny & Families & Mean & Std. Dev. & CV\% \\
\hline \multirow[t]{2}{*}{1} & 1 & S1 & 48 & 2648 & 696 & 26 \\
\hline & & HS & & 2130 & 776 & 36 \\
\hline \multirow[t]{2}{*}{2} & $1 \mathrm{~A}$ & $\mathrm{~S} 1$ & 8 & 2890 & 114 & 4 \\
\hline & & HS & & 2570 & 266 & 1 \\
\hline \multirow[t]{2}{*}{3} & 2 & S1 & 20 & 1500 & 420 & 28 \\
\hline & & HS & & 5390 & 610 & 11 \\
\hline \multirow[t]{2}{*}{4} & 3 & $\mathrm{~S} 1$ & 16 & 2880 & 349 & 12 \\
\hline & & HS & & 4640 & 506 & 11 \\
\hline \multirow[t]{2}{*}{5} & 4 & $\mathrm{~S} 1$ & 24 & 3275 & 246 & 7.5 \\
\hline & & HS & & 3790 & 342 & 9 \\
\hline \multirow[t]{2}{*}{6} & $4 \mathrm{~A}$ & $\mathrm{~S} 1$ & 16 & 3000 & 210 & 7 \\
\hline & & HS & & 3840 & 510 & 13 \\
\hline \multirow[t]{2}{*}{7} & 5 & S1 & 16 & 2661 & 298 & 11 \\
\hline & & HS & & 4000 & 380 & 9.5 \\
\hline \multirow[t]{2}{*}{8} & 6 & S1 & 6 & 1975 & 107 & 5.5 \\
\hline & & HS & & 1650 & 400 & 24 \\
\hline
\end{tabular}

Table 2: S2XS2 crosses between inbred lines and their mean yield (in g/plant) in honeycomb R-133

\begin{tabular}{llc}
\hline No & Cross & Mean \\
\hline 1 & A-27 X D-17 & 1930 \\
2 & A-27 X G-22 & 1455 \\
3 & A-8 X D-5 & 1315 \\
4 & G-35 X D-11 & 920 \\
5 & B-26 X G-27 & 785 \\
6 & B-24 X D-17 & 775 \\
7 & D-27 X G-10 & 765 \\
8 & B-36 X D-1 & 700 \\
9 & A-1 X D-2 & 630 \\
10 & B-14 X A-29 & 600 \\
11 & A-10 X B-29 & 585 \\
12 & G-10 X A-22 & 570 \\
13 & G-20 X D-8 & 570 \\
14 & PR3183 & 517 \\
\hline
\end{tabular}


control exhibited low yields of individual plants. S5 line productivity is presented in Table 3. The use of productivity index $P$ value showed that high yielding lines like D-17 and A-8 exhibited also high $P$-values. Also A-27 seemed to be a promising line according to $P$ values, although not so productive according to recorded yield $(7800 \mathrm{Kg}$ per $\mathrm{Ha}$ ) in comparison to D-17 (13000 Kg per Ha). D-17 was the best parent in crosses and their S4XS4 progenies were of high yielding performance (Table 4), usually over 10000 $\mathrm{Kg}$ per Ha.

The criteria CV and CC are presented in Table 5. According to Fasoulas $(1988,1993)$, using the CC and CV criteria we showed that the most stable S-lines were D-17, G-33 and G-35, with relative CC\% values (100, 45 and 36 respectively) and CV\% (17, 19 and 22 respectively). Best hybrids D-17 X G-33, D-17 X G-22, D-17 X A-27, Lorena (PR3183) exhibited extra low $\mathrm{CV}$ values $(9,11,10$ and $10 \%$ respectively).

Productivity index $P$, pointed out that the most productive lines like D-17 and G-33 exhibit the greatest $P$ values (Table 6). The two hybrids used as control had increased yield and $P$ values, but one s-line cross D-17XG-33 reached their productivity, followed by the crosses of best performing line D-17 to G-22, D-27 and A-8 (Table 6). High yielding lines were found in best productive crosses (Table 7). Thus, lines D-17, A-8, A-27 contributed their

\begin{tabular}{|c|c|c|c|c|c|c|}
\hline No & S-line & Mean & $\begin{array}{c}\text { productivity } \\
\text { index } P\end{array}$ & $\begin{array}{c}\text { total } \\
P\end{array}$ & $\begin{array}{c}\max \\
P\end{array}$ & $\%$ B73 \\
\hline 1 & D-17 & 13000 & 91 & 269 & 53 & 500 \\
\hline 2 & A-8 & 11050 & 76 & 170 & 32 & 425 \\
\hline 3 & G-35 & 11000 & 72 & 52 & 21 & 423 \\
\hline 4 & G-33 & 10000 & 62 & 63 & 32 & 385 \\
\hline 5 & $D-1$ & 9750 & 62 & 47 & 21 & 375 \\
\hline 6 & B-35 & 8600 & 52 & 10 & 10 & 331 \\
\hline 7 & A-29 & 8600 & 52 & 74 & 53 & 331 \\
\hline 8 & A-27 & 7800 & 48 & 395 & 53 & 300 \\
\hline 9 & G-10 & 7800 & 48 & 99 & 37 & 300 \\
\hline 10 & B-14 & 6650 & 29 & 32 & 32 & 256 \\
\hline 11 & A-22 & 6500 & 19 & 42 & 37 & 250 \\
\hline 12 & D-8 & 6000 & 10 & 5 & 5 & 231 \\
\hline 13 & G-22 & 5200 & 5 & 116 & 42 & 200 \\
\hline 14 & D-5 & 5200 & 5 & 42 & 32 & 200 \\
\hline 15 & D-2 & 4800 & 0 & 26 & 21 & 185 \\
\hline 16 & A-2 & 4550 & 0 & 42 & 21 & 175 \\
\hline 17 & D-30 & 4150 & 0 & 31 & 21 & 160 \\
\hline 18 & B-24 & 4150 & 0 & 10 & 5 & 160 \\
\hline 19 & D-27 & 3900 & 0 & 36 & 26 & 150 \\
\hline 20 & G-27 & 3650 & 0 & 5 & 5 & 140 \\
\hline 21 & B-36 & 3250 & 0 & 26 & 21 & 125 \\
\hline 22 & B73 & 2600 & 0 & 53 & 32 & 100 \\
\hline
\end{tabular}

$\operatorname{LSD}(0.05)= \pm 2300, \mathrm{CV} \%=28$, General Mean $=6750$ per se productivity in their crosses too, but in the last table Mid-parent heterosis and heterobeltiosis was low (Tables 6 and 7). Sometimes productivity of high yielding lines resulted in low or negative heterobeltiosis and Mid-parent heterosis found also low except some cases of crosses between lines with different $\mathrm{S} 1 / \mathrm{HS}$ behaviour where heterosis was satisfactory (near 50\%).

In Fig. 1, the level of productivity of lines and their crosses was presented in a bar scheme (first introduced by Greveniotis et al., 2009). Crosses were in a higher level and the most productive S-lines contributed in higher yield crosses, but not in crosses to common external parent B73. Main S-line relative yield progress from S1 to S7 figured out the most productive and stable lines across years (and generations) like lines D-17, or G-33 (Fig. 2).

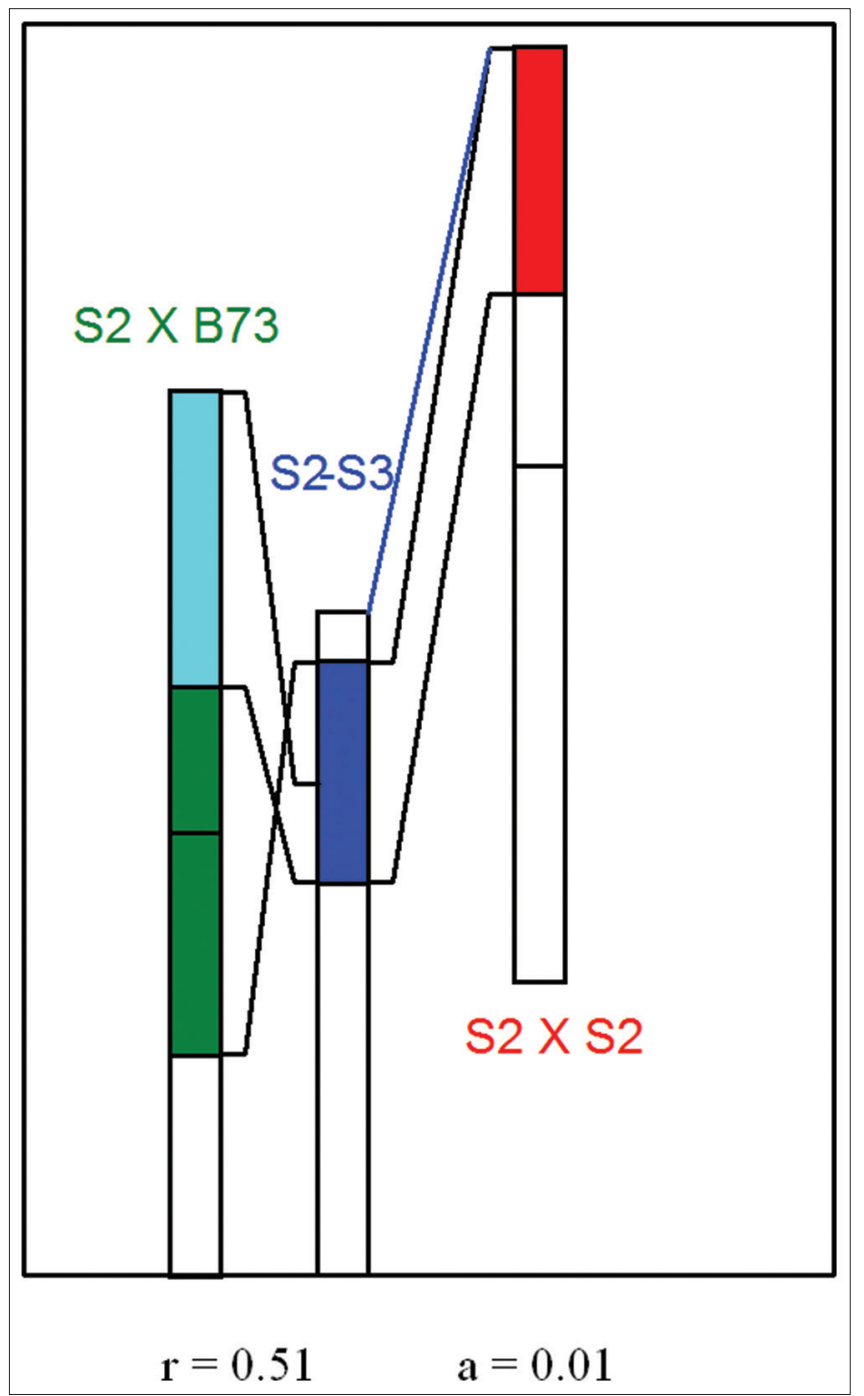

Fig 1. Yield relationships between high-yielding S2/S3 lines and their S2 crosses and crosses to B73. The contribution of yielding performance of S2, S3 lines to their crosses. Relative yield is presented schematically by colours, bars and lines of yielding performance level (the correlation coefficient $r$ is also presented, statistically significant at 0.01 level). 
Ipsilandis, et al.

Table 4: S4XS4 crosses in three RCBs (set 1, 2, 3) Mean yield in Kg per Ha, yield (\%) of the mean control (mean of PR3183 and PR3165 yield) and productivity index $P$

\begin{tabular}{|c|c|c|c|c|c|c|c|c|c|c|c|c|}
\hline No & Crosses set 1 & Mean & $\%$ & $P$ & Crosses set2 & Mean & $\%$ & $P$ & Crosses set3 & Mean & $\%$ & $P$ \\
\hline 1 & A-27 X G-22 & 5600 & 43 & 10 & D-17 X G-22 & 14300 & 91 & 42 & A-8 X D-5 & 10800 & 73 & 32 \\
\hline 2 & A-27 X G-35 & 8200 & 62 & 21 & D-17 X G-35 & 11700 & 74.5 & 10 & A-8 $\times$ B-14 & 10800 & 73 & 32 \\
\hline 3 & A-27 X G-33 & 8600 & 65.5 & 32 & D-17 X G-33 & 12600 & 80 & 10 & $A-8 \times A-10$ & 4150 & 27.5 & 0 \\
\hline 4 & A-27 X G-27 & 2600 & 20 & 0 & D-17 X G-27 & 10800 & 68.5 & 5 & A-8 $\times$ B-29 & 8200 & 55.5 & 21 \\
\hline 5 & A-27 X B-24 & 5350 & 40.5 & 5 & D-17 X B-24 & 9900 & 63 & 5 & $A-8 \times D-8$ & 4950 & 34 & 0 \\
\hline 6 & A-27 X D-27 & 3250 & 25 & 0 & D-17 X D-27 & 11700 & 74.5 & 10 & A-8 X G-22 & 10800 & 73 & 32 \\
\hline 7 & A-27 X G-5 & 9350 & 71 & 37 & D-17 X G-5 & 11450 & 73 & 5 & $A-8 \times A-2$ & 8300 & 56 & 21 \\
\hline 8 & $A-27 \times G-10 b$ & 7800 & 59.5 & 21 & D-17 X G-10b & 12100 & 77 & 10 & B-26 X G-27 & 6900 & 46.5 & 0 \\
\hline 9 & A-27 X B-36 & 2350 & 18 & 0 & D-17 X B-36 & 11300 & 72 & 5 & D-27 X G-10 & 10150 & 68.5 & 26 \\
\hline 10 & A-27 X D-1 & 8200 & 63 & 21 & D-17 X D-1 & 8700 & 55.5 & 0 & B-36 X D-1 & 9750 & 66 & 21 \\
\hline 11 & A-27 X D-2 & 8200 & 63 & 21 & D-17 X D-2 & 10900 & 69.5 & 5 & A-27 X D-17 & 11600 & 77.5 & 53 \\
\hline 12 & A-27 X G-10a & 9350 & 71 & 37 & D-17 X G-10a & 10400 & 66 & 5 & A-27 X A-8 & 4400 & 30 & 0 \\
\hline 13 & A-27 X B-35 & 3000 & 23 & 0 & D-17 X B-35 & 11850 & 75 & 10 & A-8 X D-17 & 10900 & 74.5 & 32 \\
\hline 14 & $A-22 \times D-30$ & 7150 & 54.5 & 21 & D-17 X D-30 & 12750 & 81 & 10 & $D-17 \times A-27 b$ & 8300 & 56 & 21 \\
\hline 15 & A-27 X A-2 & 6500 & 50.5 & 21 & D-17 X D-5 & 12500 & 79.5 & 10 & G-35 X G-33 & 8600 & 58 & 21 \\
\hline \multirow[t]{7}{*}{16} & A-27 X B73 & 7400 & 55.5 & 21 & D-17 X B73 & 6000 & 38 & 0 & $A-8 \times B 73$ & 4800 & 33 & 0 \\
\hline & PR3183 & 12350 & 94 & 95 & PR3183 & 14450 & 92 & 42 & PR3183 & 14450 & 98 & 89 \\
\hline & PR3165 & 14050 & 106 & 95 & PR3165 & 17000 & 108 & 89 & PR3165 & 15100 & 102 & 95 \\
\hline & Mean check & & 100 & & Mean check & & 100 & & Mean check & & 100 & \\
\hline & LSD.05 $= \pm 2800$ & & & & LSD. $05= \pm 2850$ & & & & LSD.05 $= \pm 2900$ & & & \\
\hline & $C V \%=24$ & & & & $C V \%=15$ & & & & $C V \%=18$ & & & \\
\hline & General $=8600$ & & & & General $=11700$ & & & & General $=9600$ & & & \\
\hline
\end{tabular}

In general, S-line yield was improved and stabilized across years and selfing generations (Tables 3, 5, 6 and Fig. 2), contributing in high SXS crosses (Tables 2, 4, 5 and 6).

\section{DISCUSSION}

Maize yield is usually based in heterotic phenomena of heterozygote individuals that exhibit high yielding performance even under stress conditions (Duvick, 1992, 2005; Tollenaar \& Wu, 1999; Ipsilandis \& Vafias, 2005). Maize breeders balance between these main goals of breeding (yield, uniformity and stability) and the cost of developing parents to be used in the final product which is a high performance F1 hybrid (Vafias \& Ipsilandis, 2005). In our study, the continuous selfing and per se evaluation led to high yielding lines, exhibiting homozygote vigour. High yielding lines may reduce hybrid production cost and is nowadays an important parameter for breeders (Fehr 1987). Best crosses in our study D-17 X G-33, D-17 X G-22, D-17 X A-27, Lorena (PR3183) exhibited extra low CV values. Fasoulas $(1988,1993)$ stated that stability is important as much productivity and CV may be a good criterion for stability behaviour. In many studies heterozygosity is accompanied by productivity and stability (Ipsilandis et al., 2006; Fasoula, 2009). It seems that dispersed heterozygous genes ensure a better balance in their genomes (Kearsey \& Pooni, 1992; Duvick, 1992, 2005).
Table 5: S6 line per se and S5XS5 crosses productivity and stability according to the two criteria: CV and CC (relative combined criterion)

\begin{tabular}{|c|c|c|c|c|c|}
\hline S6 Line & CV\% & $\mathrm{CC} \%$ & Crosses & CV\% & $\mathrm{CC} \%$ \\
\hline D-17 & 17 & 100 & D-17 × G-33 & 9 & 98 \\
\hline G-33 & 19 & 45 & D-17 × G-22 & 11 & 88 \\
\hline G-22 & 28 & 14 & $\mathrm{D}-17 \times \mathrm{D}-27$ & 17 & 47 \\
\hline G-35 & 22 & 36 & $\mathrm{D}-17 \times \mathrm{A}-8$ & 14 & 51 \\
\hline D-1 & 28 & 20 & D-17 × G-27 & 24 & 27 \\
\hline A-27 & 44 & 8 & D-17 × B-24 & 15 & 41 \\
\hline G-10 & 32 & 12 & A-27 X G-10 & 17 & 27 \\
\hline D-30 & 22 & 9 & A-27 X D-17 & 10 & 58 \\
\hline D-8 & 38 & 6 & D-17 X D-2 & 39 & 8 \\
\hline D-2 & 22 & 10 & A-8 X D-8 & 37 & 5 \\
\hline A-8 & 50 & 6 & A-27 X G-35 & 27 & 12 \\
\hline A-2 & 36 & 3 & D-17 X D-30 & 16 & 26 \\
\hline G-27 & 31 & 3 & A-8 X A-2 & 17 & 20 \\
\hline B-24 & 48 & 2 & A-27 X A-8 & 26 & 9 \\
\hline D-27 & 24 & 4 & A-27 X B-24 & 15 & 10 \\
\hline B-36 & 43 & 1 & A-27 X B-36 & 45 & 1 \\
\hline- & & & A-27 X D-27 & 33 & 2 \\
\hline- & & & A-27 X G-27 & 50 & 1 \\
\hline \multirow[t]{2}{*}{ B73 } & 30 & 1 & PR3183 & 10 & 100 \\
\hline & & & PR3165 & 15 & 90 \\
\hline
\end{tabular}

In our study, selfing and per se evaluating led to high yielding S7 maize lines, a promising material to be used as parents for crosses (Ipsilandis, 1996). Their crosses to common foreign parent led to limited heterotic phenomena and relative low yielding performance. Heterobeltiosis was found near zero or 


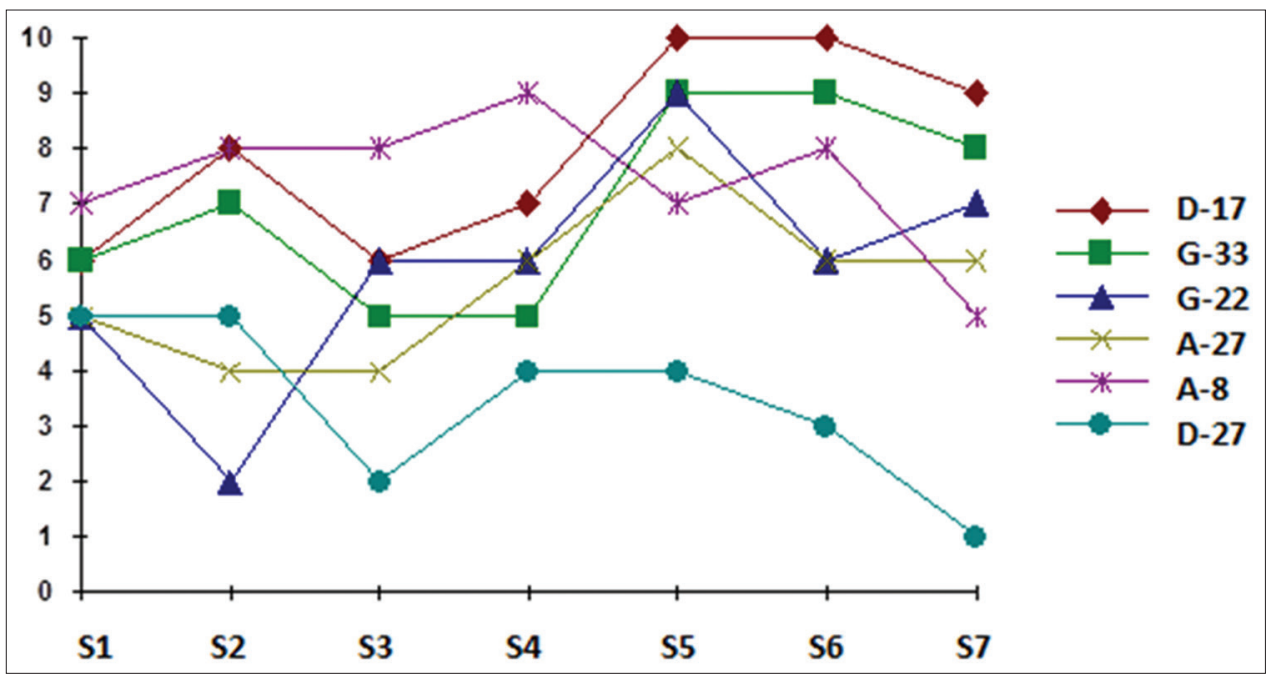

Fig 2. Main S-line relative yield progress from S1 to S7 (climax 1 to 10).

\begin{tabular}{|c|c|c|c|c|c|c|c|c|c|}
\hline No & S6 lines & Yield & $P$ & $\%$ B73 & Crosses S5XS5 & Yield & $P$ & $\% M C$ & $\% \mathrm{C}$ \\
\hline 1 & $\mathrm{D}-17(1 \mathrm{~A})$ & 10400 & 100 & 372 & PR3165 & 16750 & 95 & 107 & 115 \\
\hline 2 & D-17 (3) & 8700 & 70 & 312 & D-17 X G-33 & 14700 & 65 & 94 & 101 \\
\hline 3 & D-17 (1) & 8650 & 70 & 309 & PR3183 & 14400 & 60 & 93 & 100 \\
\hline 4 & G-33 & 8450 & 65 & 302 & D-17 X G-22 & 14300 & 60 & 92 & 99 \\
\hline 5 & G-22 & 7950 & 55 & 284 & D-17 X D-27 & 14300 & 60 & 92 & 99 \\
\hline 6 & G-35 & 7650 & 55 & 274 & D-17 X A-8 & 14150 & 60 & 91 & 98 \\
\hline 7 & D-1 & 6900 & 55 & 246 & D-17 X G-27 & 13800 & 60 & 88 & 95 \\
\hline 8 & $A-27$ & 6750 & 50 & 242 & D-17 X B-24 & 12600 & 30 & 81 & 87 \\
\hline 9 & G-10 & 6500 & 40 & 232 & A-27 X G-10 & 11300 & 25 & 73 & 78 \\
\hline 10 & D-30 & 5200 & 35 & 186 & A-27 X D-10 & 10800 & 20 & 69 & 74 \\
\hline 11 & D-8 & 5050 & 30 & 181 & D-17 X D-2 & 10400 & 20 & 67 & 72 \\
\hline 12 & D-2 & 4950 & 25 & 177 & A-8 X D-8 & 10150 & 20 & 65 & 70 \\
\hline 13 & $A-8$ & 4300 & 5 & 153 & A-27 X G-35 & 10000 & 20 & 64 & 69 \\
\hline 14 & $A-2$ & 3500 & 0 & 125 & D-17 X D-30 & 9900 & 20 & 63 & 68 \\
\hline 15 & G-27 & 3400 & 0 & 121 & $A-8 \times A-2$ & 9100 & 20 & 58 & 62 \\
\hline 16 & B-24 & 3250 & 0 & 116 & A-27 X A-8 & 8450 & 20 & 54 & 58 \\
\hline 17 & B73a & 3000 & 0 & 107 & A-27 X B-24 & 6250 & 0 & 40 & 43 \\
\hline 18 & B-36 & 2850 & 0 & 102 & A-27 X B-36 & 4550 & 0 & 29 & 31 \\
\hline 19 & D-27 & 2750 & 0 & 98 & A-27 X D-27 & 4550 & 0 & 29 & 31 \\
\hline 20 & $\mathrm{~B} 73 \mathrm{~b}$ & 2600 & 0 & 93 & A-27 X G-27 & 4400 & 0 & 28 & 30 \\
\hline & \multicolumn{4}{|c|}{$\mathrm{LSD}_{.05}= \pm 1590$} & \multicolumn{5}{|l|}{$\mathrm{LSD}_{.05}= \pm 2030$} \\
\hline & \multicolumn{4}{|c|}{$C V \%=20$} & \multicolumn{5}{|c|}{$\mathrm{CV} \%=13$} \\
\hline & \multicolumn{4}{|c|}{ General mean $=5600$} & \multicolumn{5}{|c|}{ General mean $=10850$} \\
\hline
\end{tabular}

negative, proving that such kind of parents cannot contribute in high yielding crosses because of the accumulation of useful additive alleles in one parent that are not favoured in heterozygote condition (Ipsilandis \& Koutsika-Sotiriou, 2000). Fasoulas $(1988,1993)$ depicted the importance of extensive additive gene action for heritability and productivity, and additive gene action in our study was always present because of the proper per se selection of S-lines. Ipsilandis (1996) showed that this kind of selection may improve productivity of inbred lines, with positive impact on heritability and stability. Ipsilandis et al. (2006) recorded various criteria for developing second-cycle hybrids in maize, exploring useful additive gene action. In our study, we used $\mathrm{S} 1 / \mathrm{HS}$ for oriented crosses to a more reasonable basis by combining lines with different behaviour in per se and cross yielding performance. Differences in HS/S1 performance also affect the kind of gene action in developing final inbred lines (Ipsilandis \& Koutsika-Sotiriou, 2000).

The three criteria used differences in heterobeltiosis, crosses to common parent and between S lines. Low heterobeltiosis is accompanied by high yielding performance of S-lines and 


\begin{tabular}{|c|c|c|c|c|c|c|c|c|c|}
\hline Crosses & $A \%$ & $B \%$ & AM\% & MPA & MPB & MPM & HBA & HBB & HBM \\
\hline \multicolumn{10}{|c|}{ High X High yielding S1 } \\
\hline D-17 X G-33 & 80 & 94 & 87 & +10 & +56 & +33 & -3 & +41 & +19 \\
\hline D-17 X A-8 & 75 & 91 & 83 & -3 & +93 & +45 & -10 & +36 & +13 \\
\hline \multicolumn{10}{|c|}{ High X Middle yielding S1 } \\
\hline D-17 X G-22 & 91 & 92 & 92 & +57 & +55 & +56 & +10 & +38 & +24 \\
\hline D-17 X D-2 & 69 & 67 & 68 & +3 & +36 & +20 & -16 & 0 & -8 \\
\hline A-27 X G-35 & 62 & 64 & 63 & +3 & +39 & +21 & -13 & +31 & +9 \\
\hline$A-8 \times D-8$ & 34 & 65 & 50 & -37 & +120 & +41 & -51 & +100 & +25 \\
\hline D-17 X A-27 & 77 & 69 & 73 & +18 & +26 & +22 & -5 & +4 & -0.5 \\
\hline$A-8 \times A-27$ & 48 & 54 & 51 & -50 & +53 & +1 & -58 & +25 & -17 \\
\hline A-27 X G-10 & 71 & 73 & 72 & +43 & +69 & +56 & +43 & +67 & +55 \\
\hline \multicolumn{10}{|c|}{ High X Low yielding S1 } \\
\hline D-17 X D-27 & 74 & 92 & 83 & +38 & +118 & +78 & -10 & +38 & +14 \\
\hline D-17 X G-27 & 68 & 88 & 78 & +30 & +100 & +65 & -17 & +33 & +8 \\
\hline D-17 X B-24 & 73 & 81 & 77 & +19 & +85 & +52 & -21 & +21 & 0 \\
\hline$D-17 \times D-30$ & 81 & 63 & 72 & +48 & +27 & +38 & -2 & -5 & -3 \\
\hline $\mathrm{A}-8 \times \mathrm{A}-2$ & 56 & 58 & 57 & +13 & +133 & +73 & -20 & +112 & +46 \\
\hline \multicolumn{10}{|c|}{ Middle X Low yielding S1 } \\
\hline A-27 X B-24 & 40 & 40 & 40 & +6 & +27 & +16 & -19 & -6 & -13 \\
\hline A-27 X B-36 & 19 & 29 & 24 & -48 & -3 & -25 & -63 & -31 & -47 \\
\hline A-27 X D-27 & 25 & 29 & 27 & -33 & -4 & -19 & -55 & -33 & -44 \\
\hline A-27 X G-27 & 20 & 28 & 24 & -45 & -13 & -29 & -60 & -35 & -47 \\
\hline \multicolumn{10}{|l|}{ Checks } \\
\hline PR3165 & 106 & 107 & 106 & & & & & & \\
\hline PR3183 & 94 & 93 & 94 & & & & & & \\
\hline Mean check & 100 & 100 & 100 & & & & & & \\
\hline
\end{tabular}

High $>8500 \mathrm{Kg}$ per Ha per se yield of parent S lines

Middle $>4800$ and $<8500 \mathrm{Kg}$ per Ha per se yield of parent $\mathrm{S}$ lines

Low $<4800 \mathrm{Kg}$ per $\mathrm{Ha}$ per se yield of parent $\mathrm{S}$ lines

crosses between these improved lines were generally high, but they based their productivity mainly on additive gene action and not heterozygotic superiority (Ipsilandis et al., 2005). Foreign common parent with poor per se performance lead to low yielding cross performance, proving that the basis of productivity of new crosses was depended mainly on favourable gene action (Ipsilandis et al., 2005). Perse evaluation increased line yield and resulted in crosses at satisfied yield level of productivity partly based on additive alleles possessing many homozygotic gene loci. Prognostic criteria of honeycomb methodology on parent lines involved Productivity index $P$, $\mathrm{CV}$ and CC. In our study CV proved to be a good criterion to estimate stability, but CC was a little confusing for the productivity of crosses, in comparison to S-lines where the most productive showed high CC values. Especially for crosses, the CC results were in disagreement to other criteria, like yielding performance, not revealing the most productive genotypes. Thus, $\mathrm{CC}$ was not a proper criterion for selecting crosses and it should be avoided. Productivity index $P$, although a difficult to use statistic, exhibited the superiority of the best lines. The top-yielding lines such as D-17, G-33 etc., showed high yields and simultaneously high $P$ in all comparisons.

\section{CONCLUSIONS}

S1/HS comparisons were used for targeted crosses to by combining lines with different behaviour in per se and cross yielding performance. Differences in S1/HS performance also affect the kind of gene action in developing final inbred lines.

Selfing and per se yield evaluation led to high yielding S7 maize lines, a promising material to be used as parents for crosses. Their crosses to common foreign parent led to limited heterotic phenomena and relative low yielding performance. Heterobeltiosis was found near zero or negative, proving that such kind of parents cannot contribute in high yielding crosses because of the accumulation of useful additive alleles in one parent that are not favoured in heterozygote condition.

Crosses between improved lines developed by the certain procedure generally exhibited high yielding performance mainly based on additive gene action and not heterozygotic superiority. Foreign common parent, with relatively poor per se performance, lead crosses to low yielding 
performance, being an additional proof that the basis of productivity of new crosses was depended mainly on favourable additive gene action.

Prognostic breeding is more accurate when selection is applied for exploitation of additive gene action. CV proved to be a good criterion for stability estimations, but CC was confusing for estimating the productivity of crosses, being more accurate in case of S-lines where the most productive showed high CC values. Productivity index $P$ exhibited the superiority of the best lines.

\section{ACKNOWLEDGEMENT}

Dedicated to the Greek breeder Apostolos Fasoulas.

\section{REFERENCES}

Bauman, L. F. 1981. Review of Methods Used by Breeders to Development Superior inbreds. Proceedings of the $36^{\text {th }}$ Annual Corn Sorghum Industry Research Conference. American Seed Trade Association, Washington, DC, pp. 199-208.

Coors, J. G. 1988. Response to four cycles of combined Half-sib and S1 family selection in Maize. Crop Sci. 28: 91-896.

Crow, J. F. 2000. The rise and the fall of overdominance. Plant Breed. Rev. 17: 225-257.

Duvick, D. N. 1992. Genetic contributions to advances in yield of U.S. maize. Maydica. 37: 69-79.

Duvick, D. N. 1996. Plant breeding, an evolutionary concept. Crop Sci. 36: 539-548.

Duvick, D. N. 1999. Heterosis: Feeding people and protecting natural resources. In: Coors, J. G. and S. Pandey, (Eds.), The Genetic and Exploitation in Crops. American Society of Agronomy. Inc., Crop Science Society of America Inc., Soil Science Society of America Inc., Madison, WI.

Duvick, D. N. 2001. Biotechnology in the 1930s: The development of hybrid maize. Nat. Rev. Genet. 2(1): 69-74.

Duvick, D. N. 2005. Genetic progress in yield of United States maize (Zea mays L.). Maydica. 50: 193-202.

Falconer, D. S. 1960. Introduction to Quantitative Genetics. $1^{\text {st }}$ ed. Oliver and Boyd, London.

Fasoula, V. A. 2008. Two Novel Whole-plant Field Phenotyping Equations Maximize Selection Efficiency. Proceedings of the $18^{\text {th }}$ Eucarpia General Congress. Modern Cultivar Breeding for Present and Future Needs. Valencia, Spain, pp. 361-365.

Fasoula, V. A. 2009. Selection of High Yielding Plants Belonging to Entries of High Homeostasis Maximizes Efficiency in Maize Breeding. Proceedings of the International Eucarpia Conference in Maize and Sorghum Breeding in the Genomics Era. Bergamo, Italy, p. 29.

Fasoula-loannides, D. A. 1992. The Impact of Positive and Negativecompetition on Plant Domestication. International Conference Development of New Crops, Jerusalem, BG University.

Fasoulas, A. C. 1981. Principles and Methods of Plant Breeding. Department of Genetics and Plant Breeding, Aristotelian University of Thessaloniki, Greece.

Fasoulas, A. C. 1985. A moving block evaluation technique for improving the efficiency of pedigree selection. Euphytica. 36: 473-478.
Fasoulas, A. C. 1988. The Honeycomb Methodology of Plant Breeding. Department of Genetics and Plant Breeding, Aristotelian University of Thessaloniki, Greece.

Fasoulas, A. C. 1993. Principles of Crop Breeding. Department of Genetics and Plant Breeding, Aristotelian University of Thessaloniki, Greece.

Fehr, W. R. 1987. Principles of Cultivar Development. $1^{\text {st }}$ ed. MacMillan Publishing Company, Ames, lowa.

Gomez, K. A. and Gomez, A. A. 1984. Statistical Procedures for Agricultural Research. John Wiley and Sons, Inc., New York.

Goulas, C. K. and Lonnquist, J. H. 1976. Combined half-sib and S1 family selection in a maize composite population. Crop Sci. 16: 461-464.

Greveniotis, V. and Fasoula, V. A. 2016. Application of prognostic breeding in maize. Crop Pasture Sci. 67: 605-620.

Greveniotis, V., O. Xanthopoulou, E. Pessios, P. Deligeorgidis, D. Stefanis and C. G. Ipsilandis. 2009. Honeycomb evaluation of barley germplasm under pre-evaluated environments. Cereal Res. Commun. 37(4): 579-586.

Greveniotis, V., E. Sioki and C. G. Ipsilandis. 2018. Estimations of fibre trait stability and type of inheritance in cotton. Czech J. Genet. Plant Breed. 54(4): 190-192.

Greveniotis, V., S. Zotis, E. Sioki and C. G. Ipsilandis. 2019. Improving pedigree selection in applied breeding of barley populations. Cereal Res. Commun. 47(1): 123-133.

Hallauer, A. R. 1979. Corn Breeding Opportunities in the 1980's. Annual Corn lowa Seed Dealers Association, Des Moines.

Ipsilandis, C. G. and M. Koutsika-Sotiriou. 2000. The combining ability of recombinant S-lines developed from an F2 maize population. J. Agric. Sci. (Cambridge). 134(2): 191-198.

Ipsilandis, C. G., P. N. Deligeorgidis, L. Giakalis, M. Koutsika, A. Papadopoulou and V. Xanthopoulos. 2005. Breeding for homozygotic superiority and stability in maize without loosing combining ability. Asian J. Plant Sci. 4: 499-506.

Ipsilandis, C. G. and B. N. Vafias. 2005. Plant density effects on grain yield per plant in Maize: Breeding implications. Asian J. Plant Sci. 4: 31-39.

Ipsilandis, C. G., I. S. Tokatlidis, B. Vafias and D. Stefanis. 2006. Criteria for developing second-cycle hybrid in maize. Asian J. Plant Sci. 5: 680-685.

Ipsilandis, K. 1996. The Possibility to Predict Combining Ability Between Maize Inbred Lines Based on Best Cross Performance. (Doctoral Dissertation), Aristotle University of Thessaloniki, Thessaloniki, Greece.

Kearsey, M. J. and H. S. Pooni. 1992. The potential of inbred lines in the presence of heterosis. In: Dattee, Y., C. Dumas and A. Gallais, (Eds.), Reproductive Biology and Plant Breeding. Springer-Verlag, London, pp. 371-386.

Koutsika-Sotiriou, M. and I. Bos. 1996. Heterosis after several numbers of cycles of mass honeycomb selection in maize. J. Genet. Breed. (Italy). 49: 361-368.

Koutsika-Sotiriou, M. 1985. Improving Combining and Yielding Ability of Maize (Zea mays L.). (Doctoral Dissertation), Aristotle University of Thessaloniki, Thessaloniki, Greece.

Smith, O. S. 1984. Comparison of effects of reciprocal recurrent selection in the BSSS(R), BSCB1(R) and BS6 population. Maydica. 24: 1-8.

Tollenaar, M. and J. Wu. 1999. Yield improvement in temperate maize is attributable to greater stress tolerance. Crop Sci. 39: 1597-1604.

Tollenaar, M., A. Ahmadzadeh and E. A. Lee. 2004. Physiological basis of heterosis for grain yield in maize. Crop Sci. 44: 2086-2094.

Vafias, B. N. and C. G. Ipsilandis. 2005. Combining ability, gene action and yielding performance in maize. Asian J. Plant Sci. 4: 50-55. 